\title{
DAVID CLARKE
}

\section{ARCHITECTS AS AGENTS FOR ORGANISATIONAL CHANGE IN NEW GENERATION LEARNING SPACES}

\section{CONTEXT}

Space, technology and pedagogy are often heralded as the key influences in the development of New Generation Learning Spaces (NGLS's) (JISC, 2006; (Radcliffe, Wilson, Powell, \& Tibbetts, 2008).The successful utilisation of these spaces and the introduction of new teaching and learning practices to them is not, however, a guaranteed outcome of a process that only focuses upon the physical aspects of NGLS design.

As an architect working in the field of education space design, my observations of recent school expansion projects where new generation learning theories were being explored reveal that the critical factors for successful implementation of new pedagogies are at least as reliant upon space and technology design, as on the presence of both a holistic approach to architectural design and the leadership of aligned organisational change

When designing new spaces, architects are perfectly positioned to explore organisational issues that need to be addressed as part of the transformation of a teaching and learning community, and yet historically they typically focus on the space being designed (making allowance for the integration of technology).

This chapter explores how a minor expansion of traditional architectural practice through the application of design thinking can assist school communities to improve their chances of successful transformation from traditional teaching and learning models to those that fully take advantage of new generation learning spaces.

\section{OBJECTIVE}

The relevance of design thinking to new generation learning space design

Design thinking seeks to transpose the processes undertaken in traditional design professions (such as architecture and engineering) into other areas of enquiry and the theory has been eagerly applied to the fields of Information Technology (Brooks Jr, 2010) and business management (Martin, 2009). However there is a growing sense that a design approach may also have significant benefit in any area of human endeavour where there are open-ended and complex problems to be solved.

Traditional problem solving seeks to manipulate a limited number of known variables to achieve a desired result (Dorst, 2011). A design thinking approach understands that there are many variables that may impact upon an outcome, some known and appreciated at the commencement of a design process, with others that are not clearly linked but which may nevertheless have a significant impact upon its success. Being open to the existence of new information can assist in the progression towards an aspired outcome. 
In order to understand how this approach may add value in the current context, it is important to understand the core logic behind the way in which designers approach problems. Dorst describes standard problem solving as utilising the following simple equation:

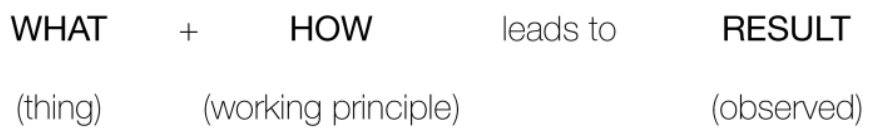

Figure 1: Traditional problem solving process

In traditional approaches to problem solving, deduction, identifies the 'what' in Figure 1; induction identifies the 'how' in Figure 1, to arrive at a somewhat logical result. In design thinking, these factors assist us to manipulate the knowns and unknowns towards a result, or abduction, where the desired RESULT creates a third factor - value for others. Thus, in design thinking, the equation is recast as:

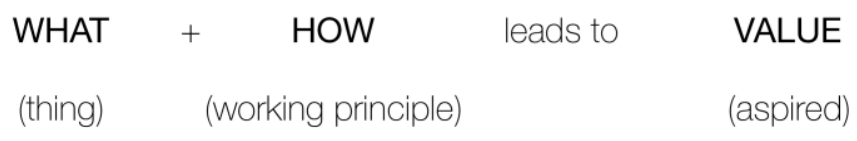

Figure 2: Design thinking process

In the unique situation of the design and inhabitation of a new school environment, this chapter argues Dorst's (2011) abduction can be recast as abduction II, providing a theoretical framework for a successful educational design project outcome. In this instance, the equation can be suggested to be:

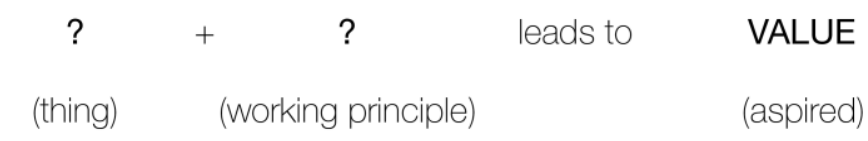

Figure 3: Design thinking remodelled for NGLEs

In this approach, we understand what aspired value we are attempting to achieve (the successful implementation of new pedagogies linked to new generation learning spaces) but we do not know what to create, nor the working principle requiring application to enable the creation to achieve success. This approach acknowledges the open-ended nature of the problem to be solved and means that we must seek two unknowns in parallel, often leading to practices that are quite separate from traditional problem solving. 
This latter approach, the 'design thinking' lens as applied to school space design, utilises those undefinable values inherent to school design and use, to facilitate a unique architect/school leadership partnership. This approach addresses the unknowns of NGLEs. More than 30 years ago, Argyris and Schon (1978, in (Mulford, 2005) understood the complex nature of educational reform, noting that those seeking to intervene in an organisation "have had to recognize that their main challenge is not to help an organization become more effective at the performance of a stable task in the light of stable purposes, but rather to help an organization restructure its purposes and redefine its task in the face of a changing environment" (p. 617).

This chapter contends that the standard approach to the design of new generation learning spaces misses an opportunity to expand architects' natural design thinking processes. These processes could be used to assist school communities to ensure successful change-management is aligned with the development of new facilities.

If architects can become the design thinker in an interdisciplinary environment that is, having empathy and understanding for people and for disciplines 'beyond one's own' (Brown \& Wyatt, 2010) - then the disparate and complex issues that contribute to successful educational project outcomes can be more comprehensively addressed. Brown and Wyatt also note that there are impediments to the successful adoption of a design thinking approach. These include an organisation's wariness of the theory and processes involved, resistance to a human-centred approach, or an inability to properly balance the disparate perspectives of users, technology and the organisation as a whole.

Although some of these impediments are less likely to arise in school settings because of the nature of the work undertaken within the 'organisation' (that is, the teaching of students, an inherently human-centred activity), there are still risks that the process will meet resistance on an organisational level because of entrenched views. The idea, for example, that an architect should be cognisant of, and actively interested in, the broader educational and organisational settings within which a design project is being undertaken may be viewed with scepticism, especially when some of the ideas being discussed during early design meetings challenge existing practices and philosophies.

Experience gained through professional architectural practice has highlighted that regardless of the skill, knowledge or intention of an architect applying a design thinking strategy to a new education design project, there are other significant factors that affect the success of the project outcome. It is the ability of architects to be aware of, and open to, these factors that could assist in linking successful pedagogical outcomes with NGLS design.

Two case studies are provided to highlight these factors. 


\section{Case Study 1 - NSW Regional Catholic High School}

The new Principal of this established regional Catholic High School inherited a school in which a number of new buildings had been designed and constructed within the previous 10-year period. He was keen to plan for the next $10-15$ years and had entreated the Catholic Education Office to undertake a new master planning process, for which an architect had been engaged.

Site visits revealed a campus with a strong organising principle (i.e 'School Street') along with some flexible learning spaces that appeared not to be being utilised in the way they were intended. Subsequent meetings with the staff cohort revealed a general dissatisfaction with the most open and flexible of the spaces - a modern, light filled open planned teaching and learning area. The space was seen as being 'too noisy' and 'too open' and was often transformed through the placement of screens and furniture in an attempt to create more traditional classroom areas.

The staff area of the school was arranged such that each staff member had an allocated permanent desk and shelf unit that over time had developed into accumulations of resources that were closely guarded and intensely private. Resource rooms revealed compactus units stacked with old VCR tapes and other out-of-date resources.

When questioned, staff acknowledged having been interviewed by the previous design architect of the open learning space with a view to having their ideas integrated into the design. When pressed, they acknowledged that there had been no additional support or professional development relating to new teaching practices that could be employed within the newly designed space.

Discussions arising from the new master plan process revealed the new Principal's strong desire to address these issues. However, it was acknowledged that the previously poorly managed introduction of the unconventional spaces may have damaged teachers' willingness to consider challenges to their existing philosophical approaches. Exploration of alternative staff arrangements and new pedagogies would therefore need to recognise these sensitivities.

\section{Case Study 2 - ACT Public Primary School}

The new Principal of this public primary school had been looking for an opportunity to apply her research into Professional Learning Communities (PLC's). The commencement of her tenure at the school coincided with a Government funded expansion of the school from a three-stream (three classrooms per year group) to a four-stream school. The Principal saw the opportunity to integrate PLC concepts into the design process and worked closely with the architect of the expansion project to ensure that staff areas and classrooms would support new approaches in both teaching and learning.

The Principal involved a core group of senior staff in espousing the PLC vision, although not all were supportive of the mooted changes to established practices. Through an extremely intense period of design, supported by a research based 
education process of the staff, a complete shift in work practice was achieved. Staff who were formerly isolated in year group enclaves were brought together through the design of a collaborative staff work area. Professional conversation was encouraged. Teaching practices were advanced to enable the opportunities afforded by the newly designed flexible learning areas to be taken advantage of. Subsequent evaluation of staff attitude revealed an almost unanimous consensus that the new arrangements were beneficial.

\section{FINDINGS / RESULTS}

Despite the differences in settings, project brief and stage of development, the two examples cited reinforced other practice-based observations that formed the core of an anticipated research direction. In essence this entails determining critical factors that affect the ability of a school to successfully implement a change in its pedagogical framework concurrent with the design of new teaching and learning spaces. This appears to be reliant on two factors being present alongside a holistic or design thinking architectural design approach: strong leadership and a commitment to teacher development. If the links can be shown, then it is contended that the consideration of these two (non-design) factors as part of the design process may assist in linking desired pedagogical outcomes with NGLS projects.

\section{Strong Leadership}

More than 20 years ago, the dilemma facing schools in an era of continuous renewal was highlighted (M Fullan, 1993). Fullan argued that teacher training, educational hierarchies and political and policy environments tended to be systems that retained the status quo and he called upon educators in the field to act as agents for change to break the impasse.

10 years on, emphasis on leadership as being key to large-scale, sustainable education reform was reinforced (Michael Fullan, 2002). In his paper 'The Change Leader', Fullan argued that the school principal of the future - the Cultural Change Principal - would be a critical component of sustainable change in a knowledge society. In his view, the concept of 'change management', a term usually associated with business management, was also relevant in an educational setting.

He listed five essential components that characterised leaders in a knowledge society:

- demonstrating social responsibility to others and the environment

- having an understanding of the change process

- possessing the ability to improve relationships

- being capable of transforming information into knowledge through a social process, and

- the ability to facilitate understanding within an environment of information overload. 
Fullan suggested that a Cultural Change Principal worked to embody these principles, resisting the temptation to drive an individual agenda within an environment hostile to change.

A Principal alone cannot carry the entire load of responsibility for organisational change, and most schools are characterised by a combination of formal and informal leadership (MacNeill, Cavanagh, \& Silcox, 2003). Principals' transformational leadership practices have been established as being directly or indirectly influential upon a wide range of school variables (Silins, Mulford, \& Zarins, 2002)

In Case Study 1, there had been an apparent lack of leadership in relation to changing pedagogies and during the introduction of new generation learning spaces to the teacher cohort. This resulted in little opportunity for teachers to understand the benefits of questioning their existing philosophies. Unsurprisingly, then, the motivation to adapt their practices to spaces that were perceived to be hostile to traditional teaching methods was low, and resentment for being forced into unfamiliar physical arrangements was commonplace. The new Principal was acutely aware of the role required of him in guiding discussion on issues that were challenging to his teacher cohort to enable reflection upon new pedagogies.

In Case Study 2, the Principal worked tirelessly to ensure that the changes she wished to introduce to the school were clear and backed by research findings. The changes were carefully planned, programmed and strategized and were undertaken within a corporate change-management framework. She created a small executive team to assist her to sell the messages throughout the school community. The team consisted of experienced teachers and the school business manager, noted in Hargreaves et al. (2001) in (MacNeill et al., 2003) as a "vital agent for creating the conditions in which school reform can succeed" (p.6).

In post-construction discussions, the Principal admitted that the path to success was extremely challenging. However, commitment to the principles of Professional Learning Communities, a willingness to discuss queries within a research-based response framework, and an expectation and management of resistance were all critical factors in the success of the programme's introduction. Considering the possibility of facing resistance at the outset of a change programme is said to have a critical impact on its success (Zimmerman, 2006)

The understanding that the design process can be used as a reinforcement of the principles being pursued was also key to the change-management success in Case Study 2. Early discussions on the design of the new staff area were used to ensure that the space and facilities provided were aligned with the desired organisational outcome. In this case, the drawing together of all staff into a central gathering space, the reduction of teacher owned resources and the provision of expansive kitchen facilities were all integrated into the design. Furniture selection (in particular large group tables for year group teachers) also played a role in the design/outcome (aspired value) nexus.

Case Study 2 demonstrates the critical role of 'The Change Leader' in the implementation of cultural / organisational / pedagogical change within a school, and how design can be leveraged to facilitate it. 


\section{Commitment to teacher development}

New school space design focusing on enabling a decentralised student-centred learning model and the integration and use of new technologies can confront the fundamental beliefs of teachers and require them to modify their practices to adapt (Ertmer, 2005). Pedagogical shifts with an emphasis on student-centred learning necessarily require teachers to view and understand course content as a complex web of opportunity accessible to a diverse student cohort. It has been understood for many years that the methods by which teachers can acquire these new skills cannot be developed using standard or traditional 'teacher training' strategies (Darling-Hammond \& McLaughlin, 1995).

Knuth and Banks' Essential Leadership Model (Knuth \& Banks, 2006) seeks to identify the elements of leadership knowledge, skills and dispositions required to effectively organise, prioritise and manage change within a school community, noting the importance of focusing on both student learning and staff professional growth.

However, supporting and facilitating these changes are known to be less familiar to staff developers who are more used to developing programs that address 'firstorder' change (e.g. training courses in the use of new technology) (Garet, Porter, Desimone, Birman, \& Yoon, 2001). Instead, they require the development of a culture that provides opportunity for teachers to critically reflect upon their practice and to be able to integrate new knowledge and beliefs about content, pedagogy and learners. The problem, as defined by Elmore (2004, in (Michael Fullan, 2006) is that:

...there is almost no opportunity for teachers to engage in continuous and sustained learning about their practice in the settings in which they actually work, observing and being observed by their classrooms and classrooms of other teachers in other schools confronting similar problems of practice. This disconnect between the requirements of learning to teach well and the structure of teachers' work life is fatal to any sustained process of instructional improvement.

In this context, the belief that newly designed spaces for teaching and learning in and of themselves can lead to shifts in teaching practice (and learning outcomes) can be dismissed. However, if the organisational and pedagogical changes that are required to facilitate shifts in teacher practice can be recognised and interwoven into the design process for new spaces, then design can be used as an agent for 'second-order' change.

In Case Study 1, the teacher cohort confirmed that as part of the design process for the recent new facilities there had been no professional development that encouraged them to consider the possibilities for new teaching and learning systems in either pedagogical or methodological terms. Staff were hostile to the new spaces and dismissive of the process that resulted in new rooms that were considered 'unworkable'. 
In Case Study 2, the Principal programmed a range of professional development activities, including site visits to demonstration NGLS schools and guided discussions between staff during the design process. Staff overcame their initial resistance to changes in practice and are now universally accepting of the new pedagogical framework and are willingly learning to implement it within the new spaces

\section{CONCLUSIONS}

These two disparate cases support the claim that, for the design of new teaching and learning areas to successfully allow the introduction of new constructivist pedagogies, the design process must be undertaken within the context of an aligned cultural and organisational change.

To further test if this belief is broadly applicable, it is suggested that a range of educational projects with an NGLS focus be audited, post completion, to determine the following:

- To what extent were the designing architects cognisant of and involved with the parallel processes of organisational change within the broader school community in the transition to new pedagogies offered by the newly designed facilities?

- Was there a leadership strategy in place prior to the commencement of the design process, and if so, what form did it take?

- Was a regime of professional development for teachers, and more broadly, consultation with other stakeholders (students, parents, community groups) put in place as part of the design process, and was the architect involved as a part of this regime?

- Have there been observable changes in teaching and learning practices afforded by the new spaces?

- To what extent have the teaching philosophies of school staff (across all levels) altered as a consequence of this process?

\section{IMPLICATIONS FOR TEACHERS AND DESIGNERS}

Most stakeholders in a new school design project commence with excellent intentions and high hopes for success. Siloed thinking on both sides of the design equation can interfere with that success.

If future research supports the observations noted in this chapter, then it may form the basis for the development of tools for both designers and educators to improve the opportunities for successful transition to new pedagogies through the design of new teaching and learning spaces. For example, it may be possible, with the assistance of school policy advisers and professional development providers, to develop pre-design checklists to assist schools to ensure that the design process is undertaken within an aligned organisational change framework.

Furthermore, it may be possible to develop specific tools for designers to guide their briefing and design processes to ensure that full recognition is being given to 
the broader social and organisational framework within which the project is being undertaken.

Research into ways in which the design process can assist in delivering successful teaching and learning outcomes within the rapidly changing education landscape is critical.

Education facility planners and designers are not educators, but they need to understand education. They cannot drive change, but they must know how to facilitate it.

\section{REFERENCES}

Brooks Jr, F. P. (2010). The design of design: Essays from a computer scientist: Pearson Education.

Brown, T., \& Wyatt, J. (2010). Design thinking for social innovation.

Darling-Hammond, L., \& McLaughlin, M. W. (1995). Policies that support professional development in an era of reform. Phi delta kappan, 76(8), 597-604.

Ertmer, P. A. (2005). Teacher pedagogical beliefs: The final frontier in our quest for technology integration? Educational technology research and development, 53(4), 25-39.

Fullan, M. (1993). Why teachers must become change agents. Educational leadership, 50(6), 12.

Fullan, M. (2002). The change leader. Educational leadership, 59(8), 16-20.

Fullan, M. (2006). Leading professional learning. School Administrator, 63(10), 10.

Garet, M. S., Porter, A. C., Desimone, L., Birman, B. F., \& Yoon, K. S. (2001). What makes professional development effective? Results from a national sample of teachers. American educational research journal, 38(4), 915-945.

Knuth, R. K., \& Banks, P. A. (2006). The essential leadership model. Nassp Bulletin, 90(1), 4-18.

MacNeill, N., Cavanagh, R. F., \& Silcox, S. (2003). Pedagogic principal leadership. Management in Education, 17(4), 14-17.

Martin, R. L. (2009). The design of business: why design thinking is the next competitive advantage: Harvard Business Press.

Mulford, B. (2005). Organizational learning and educational change. In A. Hargreaves, A. Lieberman, M. Fullan \& D. Hopkins (Eds.), Extending educational change (Vol. 2, pp. 336-361). Dordrecht, The Netherlands: Springer.

Radcliffe, D., Wilson, H., Powell, D., \& Tibbetts, B. (2008). Designing next generation places of learning: Collaboration at the pedagogy-space-technology nexus. The University of Queensland \& Australian Learning and Teaching Council, ALTC Priority Project \#627.

Silins, H. C., Mulford, W. R., \& Zarins, S. (2002). Organizational learning and school change. Educational Administration Quarterly, 38(5), 613-642.

Zimmerman, J. (2006). Why some teachers resist change and what principals can do about it. Nassp Bulletin, 90(3), 238-249.

\section{David Clarke}

Melbourne Graduate School of Education

The University of Melbourne 